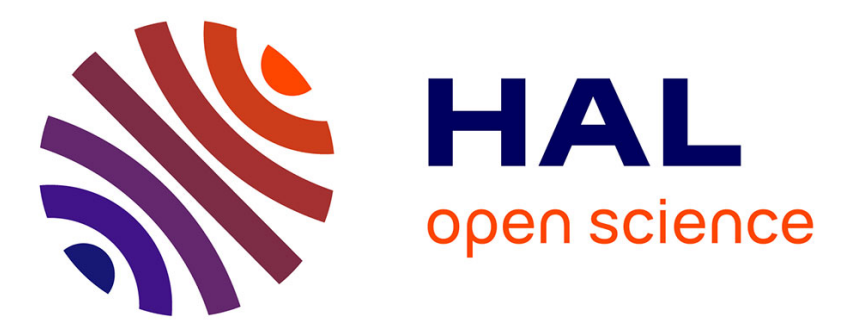

\title{
Brief Working Memory and Physiological Monitoring During a High-Altitude Expedition
}

\author{
Carine Malle, Benoît Ginon, Cyprien Bourrilhon
}

\section{To cite this version:}

Carine Malle, Benoît Ginon, Cyprien Bourrilhon. Brief Working Memory and Physiological Monitoring During a High-Altitude Expedition. High Altitude Medicine and Biology, 2016, 17 (4), pp.359-364. 10.1089/ham.2016.0022 . inserm-01470329

\section{HAL Id: inserm-01470329 https://www.hal.inserm.fr/inserm-01470329}

Submitted on 17 Feb 2017

HAL is a multi-disciplinary open access archive for the deposit and dissemination of scientific research documents, whether they are published or not. The documents may come from teaching and research institutions in France or abroad, or from public or private research centers.
L'archive ouverte pluridisciplinaire $\mathbf{H A L}$, est destinée au dépôt et à la diffusion de documents scientifiques de niveau recherche, publiés ou non, émanant des établissements d'enseignement et de recherche français ou étrangers, des laboratoires publics ou privés. 
Brief working memory and physiological monitoring during a high-altitude expedition

Carine Malle ${ }^{1,3}$, Benoît Ginon ${ }^{2}$, Cyprien Bourrilhon ${ }^{1}$

1 Institut de Recherche Biomédicale des Armées (IRBA), Brétigny-sur-Orge, France

2 Antenne médicale de l'Ecole Militaire de Haute Montagne (EMHM), Chamonix, France

3 Inserm - EPHE - UNICAEN U1077, Caen, France 


\begin{abstract}
Background: Various studies have shown the deleterious effects of high-altitude hypoxia on cognitive functions, including attention and memory. Since optimal cognitive abilities may be crucial for mountain safety, this study was aimed to assess the relevance of a brief working memory test to quickly assess cognition at high altitude. Methods: A set of physiological and cognitive measurements were collected from four professional climbers at various time points during the course of an expedition to Shishapangma $(8,043 \mathrm{~m})$. Results: Progressive highaltitude exposure induced a classical physiological response (i.e. decreased $\mathrm{SpO}_{2}$ and increased heart rate). Except for the final ascent, no participants suffered from acute mountain sickness and perceived exertion remained low. With the exception of an increased number of night awakenings, reported sleep quality was good. No working memory decline was observed in any of the participants, even at the highest altitudes. Conclusion: Altogether, these findings show that the participants were properly acclimatized to altitude. They also highlight the technical feasibility of assessing cognitive functions all along high-altitude expeditions. The direct access of tools on a smartphone may improve mountain climbing safety.
\end{abstract}




\section{INTRODUCTION}

The partial pressure of oxygen reduces exponentially with increasing altitude, leading to hypobaric hypoxia, an underlying cause of cognitive and physiological impairment at high altitude. Numerous hypobaric chamber and field studies have shown that high altitude hypoxia is responsible for cognitive deficits that may last several weeks after return to sea level. Cognitive impairments have been reported in attention (e.g., Berry et al., 1989), working memory (e.g., Kennedy, Dunlap, Banderet, Smith, \& Houston, 1989) and episodic memory (e.g., Nelson, 1982; Stivalet et al., 2000). These cognitive impairments may entail a significant safety hazard for people climbing at high altitude, as they may prompt irrational decisions leading to falls, accidents, exhaustion and death. However, the vast majority of these studies involved measuring cognitive functions at base camp (i.e. below 6,000 m). Only a few studies have been designed to explore the physiological and cognitive changes that occur during high-altitude expeditions (e.g., Grocott et al., 2010; West, 2010).

Climbers have several ways to monitor their medical status all along the expedition, te Lake Louise Self-Report Score (LLS) being widely used to diagnose Acute Mountain Sickness (AMS). The LLS can also be used to adapt the design of the expedition with the objectives of minimizing the risk of accident and maximizing chances of summit success. Hence, an extension of the acclimatization period can be decided if the LLS is high. The association of an objective measurement, such as $\mathrm{SpO}_{2}$, has been proposed to improve the diagnosis of AMS. Although optimal cognitive abilities may be crucial for safely achieving the expedition, there is no consensus on the way to quickly and accurately assess cognitive functions at high altitude. It could be of great importance in aiding medical decision-making in the field (Roach, Greene, Schoene, \& Hackett, 1998).

Working memory is a limited-capacity memory system that is responsible for the transient holding, processing, and manipulation of information (Baddeley \& Hitch, 1974). 
This cognitive function is crucial for reasoning and decision making and may be central in many climbing accidents (Wickens, Keller, \& Shaw, 2015). Thus, this study aimed at assessing the relevance of a brief working memory test to monitor cognitive performance during a high-altitude expedition.

\section{MATERIALS AND METHODS}

This project followed the tenets of the Declaration of Helsinki and was completed with ethical approval from the Institut de RechercheBiomédicale des Armées and from the Direction Centrale du Service de Santé des Armées. Each subject was briefed in details and provided written informed consent before participating.

\section{Location}

The study was conducted during a 6-week expedition, including a 2-week pre-acclimatization trek in Langtang Valley (Nepal), followed by a 4-week progressive ascent of Shishapangma (Tibet) via the South route.

The study also involved one control measuring point 8 days before the expedition (baseline) and two control measuring points 4 days and 46 days after the return to France.

\section{Participants}

Four young (29.2 \pm 1.6 years in average) men participated to this study. They were all healthy non-smoking professional climbers.

\section{Physiological assessment}

Daily physiological measurements were performed by the expedition physician, except from days during which participants were autonomously climbing. The four participants were tested one after the other, between 4 pm and 8 pm, depending on the climbing schedule.

Arterial saturation $\left(\mathrm{SpO}_{2}\right)$ and heart rate $(\mathrm{HR})$ were measured, at rest, by pulse oximetry from the fingertip (OxiPen, EnviteC, Wismar, Germany). Rest conditions were ensured 
byperforming the measurements after the participant has sat down for five minutes. High altitude environmental conditions, including cold temperature and increased sunlight, may affect the accuracy of pulse oximeter readings. For these reasons, measurement were made in a properly-heated tent and participants were told to ensure that they have warm fingers and to cover their hand to avoid the ambient light exposure.

The LLS was used for diagnosis of AMS (Roach, Bartsch, Hackett, \&Oelz, 1993). The LLS ranged from 0 to 10 , with 0 meaning no symptoms at all and 10 meaning extremely severe symptoms. A score of 3 and above, in addition to the presence of a headache, was used to establish the diagnosis of AMS. Sleep quality was assessed with a sleep agenda, allowing to calculate time in bed, total sleep time, sleep latency, the number and length of awakenings after sleep onset. Contrary to the subjective sleep component of the LLS, these measurements allow to objectively assess sleep quality. Perceived exertion was estimated with the original Borg scale (Borg, 1982), that ranges from 6 to 20, where 6 means "no exertion at all" and 20 means "maximal exertion".

During autonomous climbing, participants self-administered the same set of measurements.

\section{Cognitive assessment}

Working memory was assessed with 2 tasks: a modified version of the Paced Auditory Serial Addition Task (PASAT; Gronwall\& Sampson, 1974)] and the Wechsler Adult Intelligence Scale (WAIS) Digit Span (DS) subtest which includes: DS Forward and DS Backward. PASAT administration involves presenting a series of single digit numbers where the two most recent digits must be summed. For example, if the digits ' 3 ', ' 6 ' and ' 2 ' were presented, the participant would respond with the correct sums, which are ' 9 ' and then ' 8 '. The participant must respond prior to the presentation of the next digit for a response to be scored as correct. We modified the original version of the PASAT to make it less demanding as we expected participants to perform it very repetitively during the whole expedition, 
including during the most difficult phases of the ascent. The inter-stimulus interval (ISI) has been lengthened (4 s instead of 2 or 3s; Malle et al., 2013, 2016), as it is well-known that hypoxia is responsible for a general cognitive slowing. We also reduced the number of items (31 instead of 61), thus shortening the task ( 2 min instead of more than 4 min). The learning effect caused by the repetitive administration was reduced by creatingeight different PASAT soundtracks and by training the participants to the task before the expedition. The eight PASAT soundtracks were recorded in climbers' smartphones. Responses were written down by the physician or another climber. PASAT was used to assess attention and speed of information processing. The score is the total amount of correct responses.

DS Forward and DS Backward were both conducted verbally (1 digit per second). In the DS Forward, several digit sequences of increasing length (from 2 to 9 digits) are read out to the participant. After each sequence, the participant is asked to recall the digits in the same order. The process continues until the participant can no longer recall either the full sequence of digits or the correct order (after 2 trials). In the DS Backward, the participant is asked to repeat the digits in the reverse order. The length of the digit sequences is also increasing (from 2 to 8 digits). The DS score is the sum of the maximum amount of digits the participant was able to recall in each test. DS Forward is thought to assess the ability to store information in memory for a short period. DS Backward has additional executive control requirements to transform and manipulate information (to reverse the digit sequence), thus making it more reflective of cognitive control (Baddeley, 2012). While PASAT was performed at the base camp, at the advanced base camp and during summit climbing, the DS subtests were only performed at base camps (and thus always administered by the physician).

\section{Data analysis}

Data analysis was performed using Statistica (Statistica 10, Dell Statistica, Tulsa, Oklahoma, USA). All results were compared to baseline measurements performed 8 days 
before the expedition. For comparison of results from baseline, a Friedman repeated measures analysis of variance on ranks was first performed and, if significant, a Wilcoxon matched pairs test was performed against baseline value. Statistical significance was established at $\mathrm{p} \leq$ 0.05 . 


\section{RESULTS AND DISCUSSION}

\section{Expedition profile}

The expedition profile is represented in Fig.1. The expedition began with a 13-day preacclimatization trek (D1-D13), during which a first ascent to 5,500 m (D9) was performed. The ascent of Shishapangma (D18-D43) via the South route involved establishing a base camp $(5,300 \mathrm{~m})$ from where climbers reached an "acclimatization summit" (6,650 m; D27). After 14 days acclimatization at base camp, climbers established an advanced base camp for 2 days $(5,600 \mathrm{~m})$ from which the final ascent to Shishapangma summit was launched. Climbers reached Shishapangma summit $(8,043 \mathrm{~m}$; D41) in 3 days, via 3 intermediary bivouacs at respectively 5,900 $\mathrm{m}, 6,640 \mathrm{~m}$ and 7,200 $\mathrm{m}$. The descent to the initial base camp involved one intermediary bivouac at $6,640 \mathrm{~m}$. This follow-up study also comprised one pre-evaluation 8 days before the pre-acclimatization trek (baseline) and two post-evaluations respectively 4 days (D61) and 46 days (D103) after the end of the expedition. These control measurements were performed in Chamonix (France, 1,050 m). It is also important to notice that none of the climbers used supplemental oxygen.

\section{Acute Mountain Sickness and physiological measurements}

LLS remained below 3 in every climbers during the expedition except during the final ascent to Shishapangma (from day 39 to day 41) (Fig. 2). This result indicates that all the climbers were properly acclimatized to altitude (up to $6,640 \mathrm{~m}$ ). The highest values were measured at 6,640 $\mathrm{m}$ (day 41), where the 2 participants had a score of 11 and 12 , respectively. Thus, high LLS may not be incompatible with summit success in high-level climbers.

As expected, $\mathrm{SpO}_{2}$ significantly dropped at higher altitudes (Fig.3). Hence, at day 40, as climbers established their highest bivouac at 7,200 m, mean $\mathrm{SpO}_{2}$ was $72.5 \pm 2.5 \%$ and mean HR was $122 \pm 2 \mathrm{BPM}$ (i.e. 2 times higher than baseline HR). Since hypoxia is thought to be one of the main triggers for $\mathrm{AMS}, \mathrm{SpO}_{2}$ has been suggested to be a useful tool for the 
prediction (Karinen et al. 2010) and the diagnosis (O'Connor et al. 2004) of AMS. However, most studies did not evidenceany correlation between hypoxemia and AMS (Karinen, Peltonen, Kähönen, \&Tikkanen, 2010; Roach et al., 1998). Consistently with this literature, we found no correlation between $\mathrm{SpO}_{2}$ measurements and LLS $\left(\mathrm{r}^{2}=0.1302 ; \mathrm{p}=0.1081\right)$. Interestingly, Mandolesi et al. (2014) suggested that the predictive power of $\mathrm{SpO}_{2}$ measurements may only apply to subjects suffering from severe AMS (LLS $\geq 5$ ).It should also be mentioned that $\mathrm{SpO}_{2}$ decline, out of proportion to that normally expected,is also a major diagnosis criterion for high altitude pulmonary edema, a more severe form of altitude sickness (Luks, 2015). Beside its importance for altitude sickness diagnosis, the usefulness of $\mathrm{SpO}_{2}$ measurements in the management of the ascent have been questioned. Davies et al. (2009) reported no relationship between $\mathrm{SpO}_{2}$ and summit success on the Marangu route on Kilimanjaro (5,895 m), whereas Tannheimer et al. (2002) showed that $\mathrm{SpO}_{2}$ measured on arrival at base camp was predictive of the maximum altitude reached on Broad Peak $(8,047$ m). It is now firmly accepted that a single $\mathrm{SpO}_{2}$ measurement is not sufficient to dictate whether a climber should or should not go higher.

\section{Objective sleep quality and perceived exertion}

Counter-intuitively, mean total sleep time was significantly increased in comparison to the baseline for almost every night. However, there was a significant increase in the number of awakenings after sleep onset when a new altitude level has been reached. Hence, the number of awakenings was significantly higher on the first two days spent above 4,500 m (day 8: $8 \pm 1$ and day 9: $6 \pm 2$ ) and on the first two days spent above 5,600 $\mathrm{m}$ (day 25: $5 \pm 1$ and day 26: $6 \pm 1$ ). Awakenings were also more numerous on the night before the summit day (day 40: $10 \pm 0$ ). The length of the awakenings and sleep latency were not significantly modified from baseline. As a result, sleep efficiency was similar to baseline, except from day $22(85.9 \pm 5.7 \%)$. Disturbances in sleep quality are often reported at high altitude and may 
result from both hypoxia and periodic breathing during sleep, i.e. oscillations in respiratory frequency and/or tidal volume. In particular, periodic breathing may contribute to the frequent awakenings we observed at each altitude threshold crossing (Weil, 2004; Zieliński et al., 2000).

Except from day $20(13.8 \pm 0.2)$, the Borg scale score was not significantly changed from baseline. This result indicates that all climbers were in good shape during the whole expedition.

\section{Cognitive assessment}

The main results are summarized in Table 1. Unlike West (2010), no significant difference was found in any of the three cognitive tasks. In particular, we observed no decrement in PASAT performance, even at the highest altitudes. Except from the day 16, every participant always scored between 28 and 30. Similarly, the participants' scores at the DS forward and at the DS backward were comprised between 4 and 8 and between 3 and 7, respectively. This lack of decrement in comparison to baseline measurements can be interpreted in three distinct ways. First, it may be attributable to a ceiling effect, reflecting the poor sensitivity of these tasks to terrestrial hypoxia. Although we previously showed that the PASAT $4 \mathrm{~s}$ was very sensitive to acute (aeronautical) hypoxia (Malle et al., 2013, 2016), it may not be sensitive enough to terrestrial hypoxia. Indeed, Wang et al. (2013) showed that acetazolamide treatment during high-altitude exposure reduced PASAT performance, but only with an inter-stimulus interval of $1.2 \mathrm{~s}$. One may think that a more prolonged hypoxia exposure leads to sharper cognitive impairments that cannot be evidenced in easy tasks. Secondly, the lack of working memory decline may indicate that the four participants were cognitively efficient due to proper acclimatization, as it is suggested by the other physiological measurements, notably objective sleep quality. This hypothesis is in line with previous studies suggesting that increased sleepiness may play a seminal role in cognitive impairments observed at high 
altitude (e.g., Kryskow, Beidleman, Fulco, \&Muza, 2013). At last, this lack of cognitive decrement may be explained by the very low number of participants. Indeed, one great limitation of our study is that it involved a sample of only fourclimbers. Moreover, during the final ascent to Shishapangma Summit (D38-D41), i.e. the most demanding part of the expedition, only two of them performed the PASAT above 5,600 $\mathrm{m}$ and only one above 5,900 $\mathrm{m}$ while the others chose to focus on the ascent. This may be a bias as the participants who accepted to perform the test may have been those in better shape.

Cognitive assessments performed on D61 and D103 (4 days and 46 days after the return to France, respectively) showed no decrease in working memory performance in comparison to baseline assessment, suggesting a lack of negative short- and long-term effects of this prolonged high-altitude exposure on working memory. 


\section{CONCLUSION}

In summary, our findings show that the expedition design allowed the four climbers to be properly acclimatized to altitude, resulting in a preservation of working memory abilities. Moreover, this study shows that the real-time monitoring of working memory all along an expedition is technically feasible. Although the PASAT combines the advantages of 1) being storable on a smartphone (i.e. no supplemental material to carry) and 2) being very simple to administer and to score, this task may be too easy for acclimatized subjects, at least with an ISI of $4 \mathrm{~s}$. Later studies could use a shorten ISI or another working memory test, like the nback task (Kirchner, 1958). More complex cognitive processes such as decision making could also been investigated. Moreover, our study highlights the usefulness of smartphones in assessing cognitive functions. With the development of pulse oximeters for smartphones (e.g., $\mathrm{iSpO}_{2}$, Masimo Corporation, Irvine, Canada), one great perspective is the possibility to combine $\mathrm{SpO}_{2}$ measurement, LLS, objective sleep quality and cognitive assessment to create a composite index reflecting the individual's physiological and cognitive status. This index may be useful for professional climbers but also for occasional ones, who are less familiar with altitude maladaptation symptoms. 


\section{ACKNOWLEDGMENTS}

We would like to thank the many co-workers who made this study possible. In particularly, we would like to thank the members of the GroupeMilitaire de Haute Montagne, especially those who participated to the "Shishapangma 2014" expedition: L. Albrieux, A. Bletton, M. Bonniot, S. Moatti and S. Ratel. A special thanks also goes to P. Colin and B. Lepetit for their technical and medical assistance. 


\section{REFERENCES}

Baddeley A. (2012). Working Memory: Theories, Models, and Controversies. Annu Rev Psychol 63:1-29.

Berry DT, McConnell JW, Phillips BA, Carswell CM, Lamb DG, and Prine BC. (1989). Isocapnic hypoxemia and neuropsychological functioning. J ClinExpNeuropsychol11:241251.

Borg GA. (1982). Psychophysical bases of perceived exertion. Med Sci Sports Exerc 14:377381.

Davies AJ, Kalson NS, Stokes S, Earl MD, Whitehead AG, Frost H, Tyrell-Marsh I, and Naylor J. (2009). Determinants of summiting success and acute mountain sickness on Mt Kilimanjaro (5895 m). Wilderness Environ Med 20:311-317.

Grocott MP, Martin DS, Wilson MH, Mitchell K, Dhillon S, Mythen MG, Montgomery HE, and Levett DZ. (2010). Caudwell Xtreme Everest Expedition. High Alt Med Biol 11:133137.

Gronwall D, and Sampson H. (1974). The psychological effects of concussion. Auckland: Auckland University Press.

Karinen HM, Peltonen JE, Kähönen M, and Tikkanen HO. (2010). Prediction of acute mountain sickness by monitoring arterial oxygen saturation during ascent. High Alt Med Biol 11:325-332.

Kennedy RS, Dunlap WP, Banderet LE, Smith MG, and Houston CS. (1989). Cognitive performance deficits in a simulated climb of Mount Everest: Operation Everest II. Aviat Space Environ Med 60:99-104.

Kirchner WK. (1958). Age differences in short-term retention of rapidly changing information. J ExpPsychol55:352-358.

Kryskow MA, Beidleman BA, Fulco CS, and Muza SR. (2013). Performance During Simple and Complex Military Psychomotor Tasks at Various Altitudes. Aviat Space Environ Med 84:1147-1152.

Luks AM. (2015). Physiology in Medicine: A physiologic approach to prevention and treatment of acute high-altitude illnesses. J ApplPhysiol (1985) 118:509-19.

Malle C, Bourrilhon C, Quinette P, Laisney M, Eustache F, andPiérard C. (2016). Physiological and Cognitive Effects of Acute Normobaric Hypoxia and Modulations from Oxygen Breathing. Aerosp Med Hum Perform 87:3-12. 
Malle C, Quinette P, Laisney M, Bourrilhon C, Boissin J, Desgranges B, Eustache F, and Piérard C. (2013). Working Memory Impairment in Pilots Exposed to Acute Hypobaric Hypoxia. Aviat Space Environ Med 84:773-779.

Mandolesi G, Avancini G, Bartesaghi M, Bernardi E, Pomidori L, andCogo A. (2014). Longterm monitoring of oxygen saturation at altitude can be useful in predicting the subsequent development of moderate-to-severe acute mountain sickness. Wilderness Environ Med 25:384-391.

Nelson M. (1982). Psychological testing at high altitudes. Aviat Space Environ Med 53:122126.

Roach RC, Bartsch P, Hackett PH, andOelz O. (1993). The Lake Louise acute mountain sickness scoring system. In: JR Sutton, CS Houston, and G Coates (Eds.), Hypoxia and molecular medicine. Burlington, VT: Queens City Printers, pp. 272-274.

Roach RC, Greene ER, Schoene RB, and Hackett PH. (1998). Arterial oxygen saturation for prediction of acute mountain sickness. Aviat Space Environ Med 69:1182-1185.

Stivalet P, Leifflen D, Poquin D, Savourey G, Launay JC, Barraud PA, Raphel C, and Bittel J. (2000). Positive expiratory pressure as a method for preventing the impairment of attentional processes by hypoxia. Ergonomics 43:474-485.

Tannheimer M, Thomas A, and Gerngross H. (2002). Oxygen saturation course and altitude symptomatology during an expedition to broad peak (8047 m). International Journal of Sports Medicine 23:329-335.

Wang J, Ke T, Zhang X, Chen Y, Liu M, Chen J, and Luo W. (2013). Effects of acetazolamide on cognitive performance during high-altitude exposure. NeurotoxicolTeratol35:28-33.

Weil JV. (2004). Sleep at high altitude. High Alt Med Biol5:180-189.

West JB. (2010). American Medical Research Expedition to Everest. High Alt Med Biol11:103-110.

Wickens CD, Keller JW, and Shaw C. (2015). Human Factors in High-Altitude Mountaineering. Journal of Human Performance in Extreme Environments 12.

Zieliński J, Koziej M, Mańkowski M, Sarybaev AS, Tursalieva JS, Sabirov IS, Karamuratov AS, and Mirrakhimov MM. (2000). The quality of sleep and periodic breathing in healthy subjects at an altitude of 3,200 m. High Alt Med Biol1:331-336. 


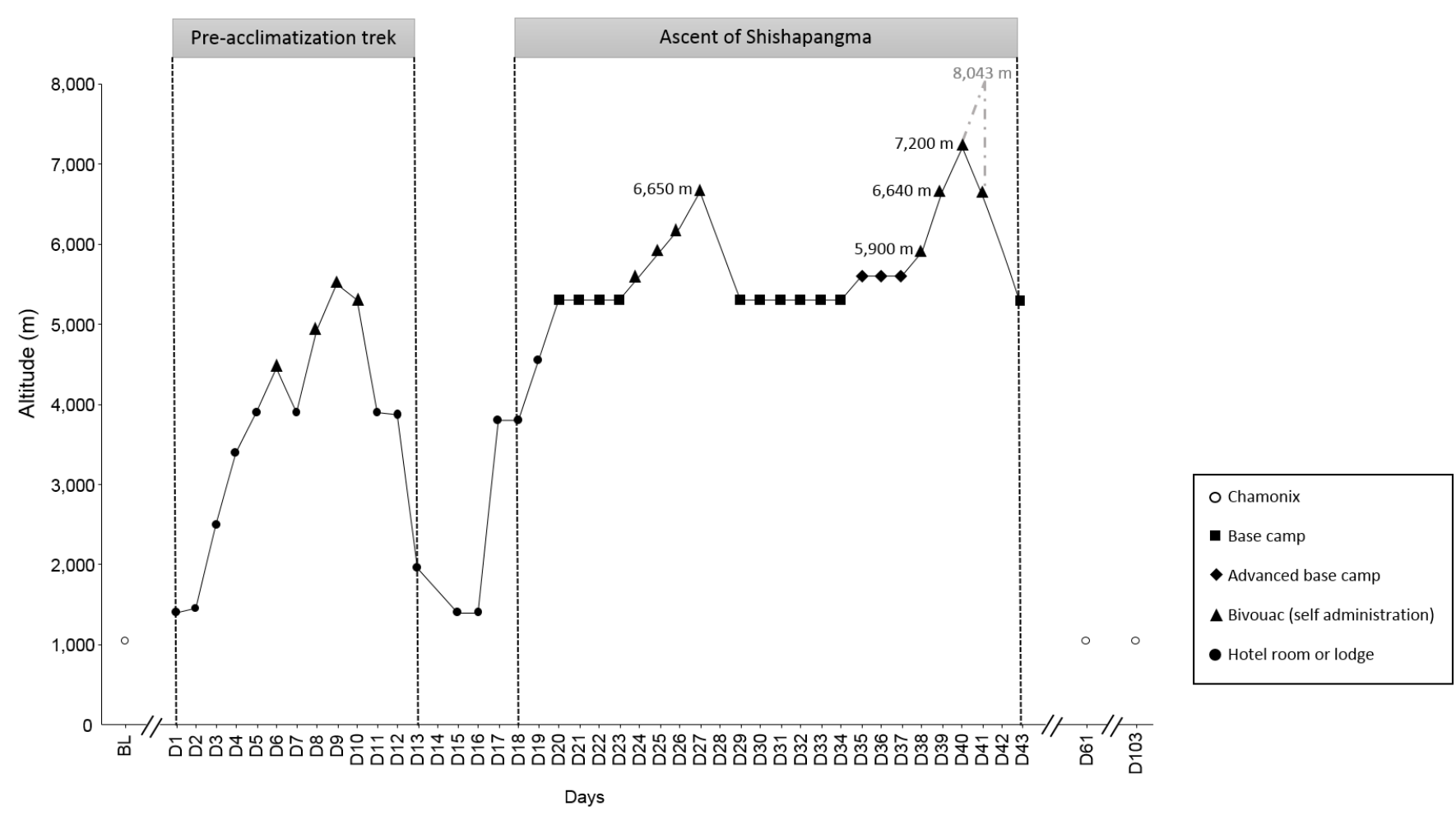

Fig.1: Expedition profile and measurement conditions. Black values on the plot indicate the altitude at which the measurements were performed. The grey dotted line associated with the grey value indicate the maximum reached altitude on the summit day (D41). BL = baseline. 


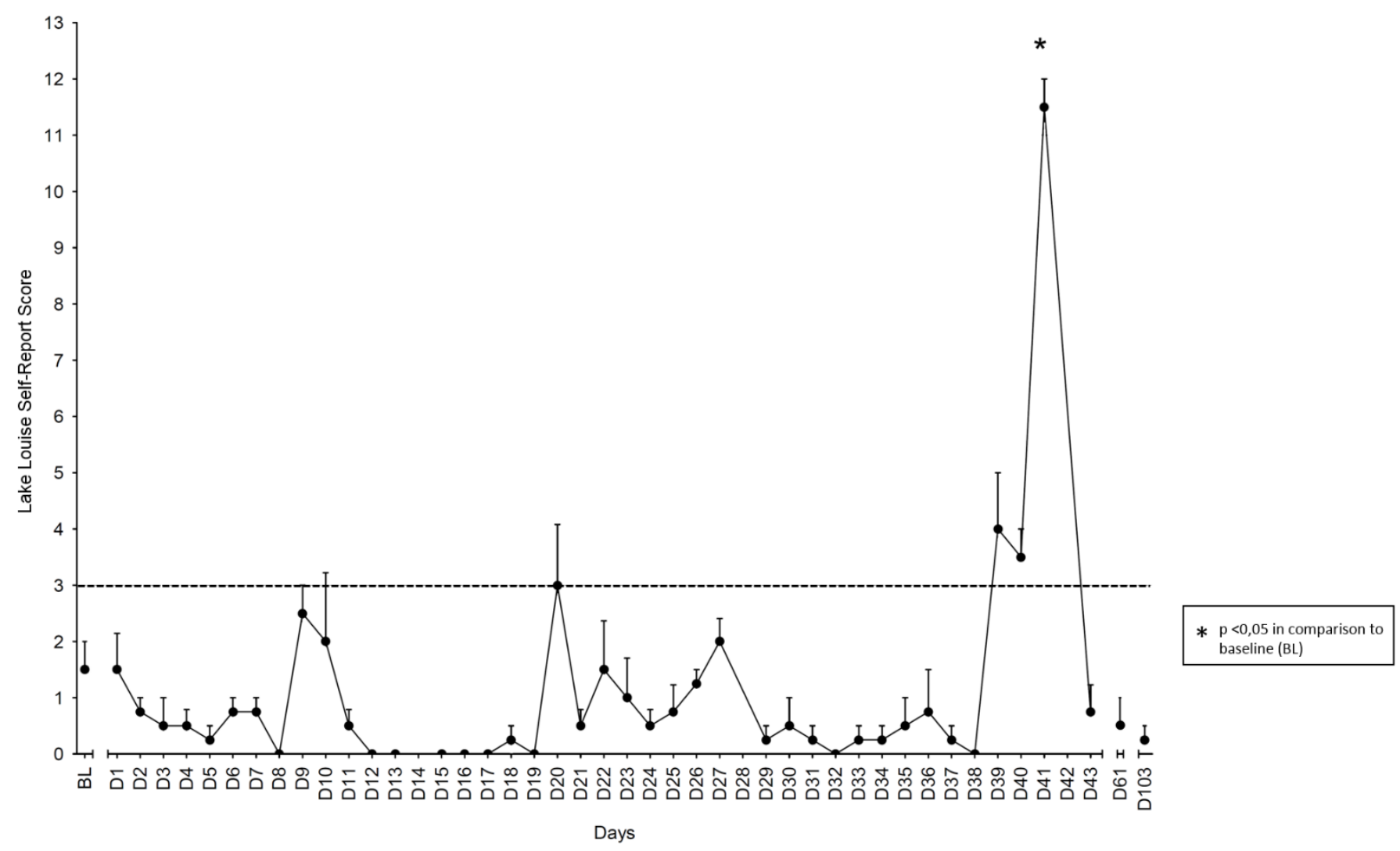

Fig.2: Evolution of the Lake Louise Self-Report Score during the expedition. The dotted horizontal line indicates the threshold for acute mountain sickness diagnosis. $\mathrm{BL}=$ baseline. Error bars pointing upward are standard error of the mean. 


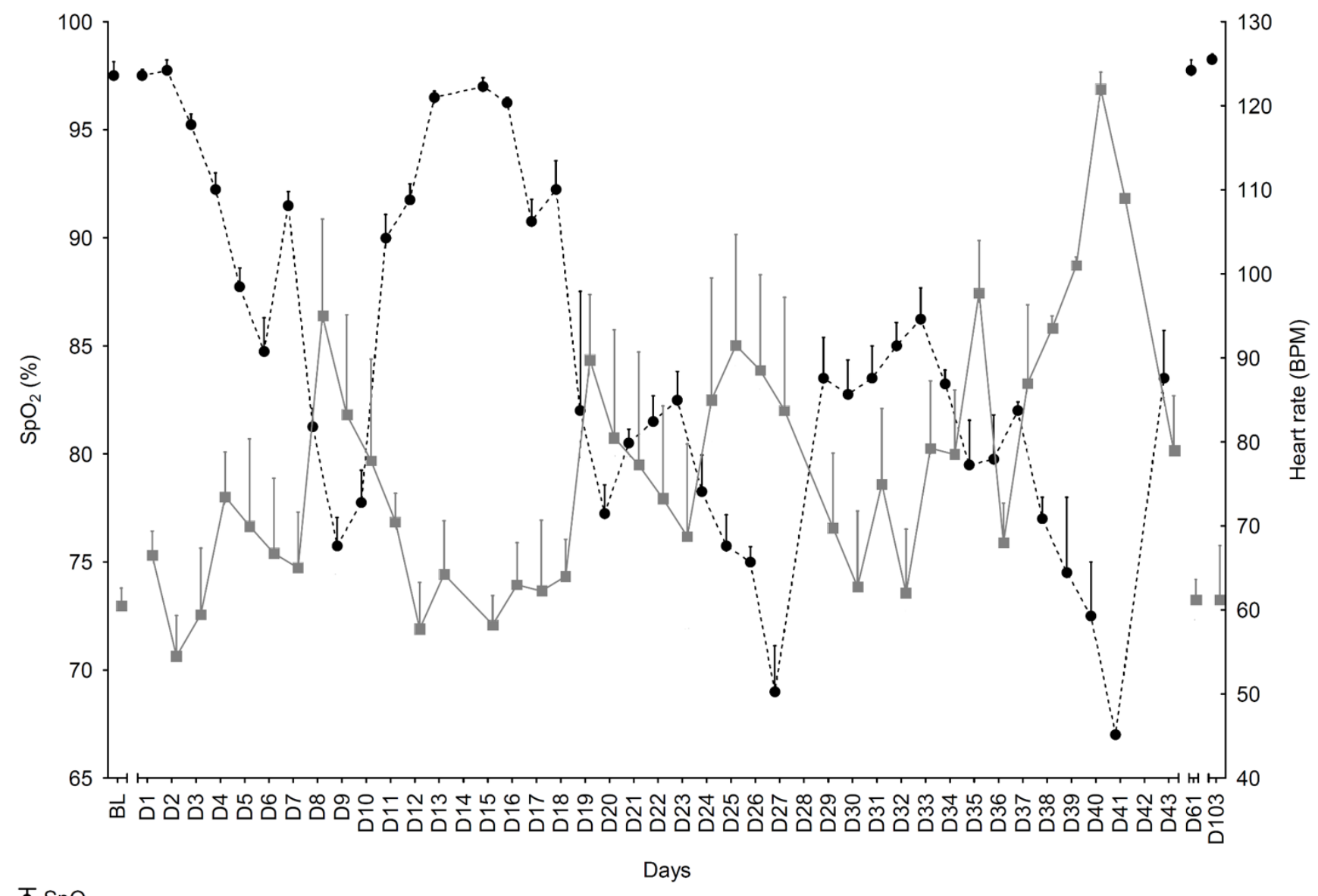

平 $\mathrm{SpO}_{2}$

포 Heart rate

Fig.3: Evolution of $\mathrm{SpO}_{2}$ and heart rate during the expedition. Grey solid line: $\mathrm{SpO}_{2}$; black dash-dot line: heart rate $\mathrm{BL}=$ baseline. Error bars pointing upward are standard error of the mean. 
Table 1. Evolution of Cognitive Performance During the Expedition

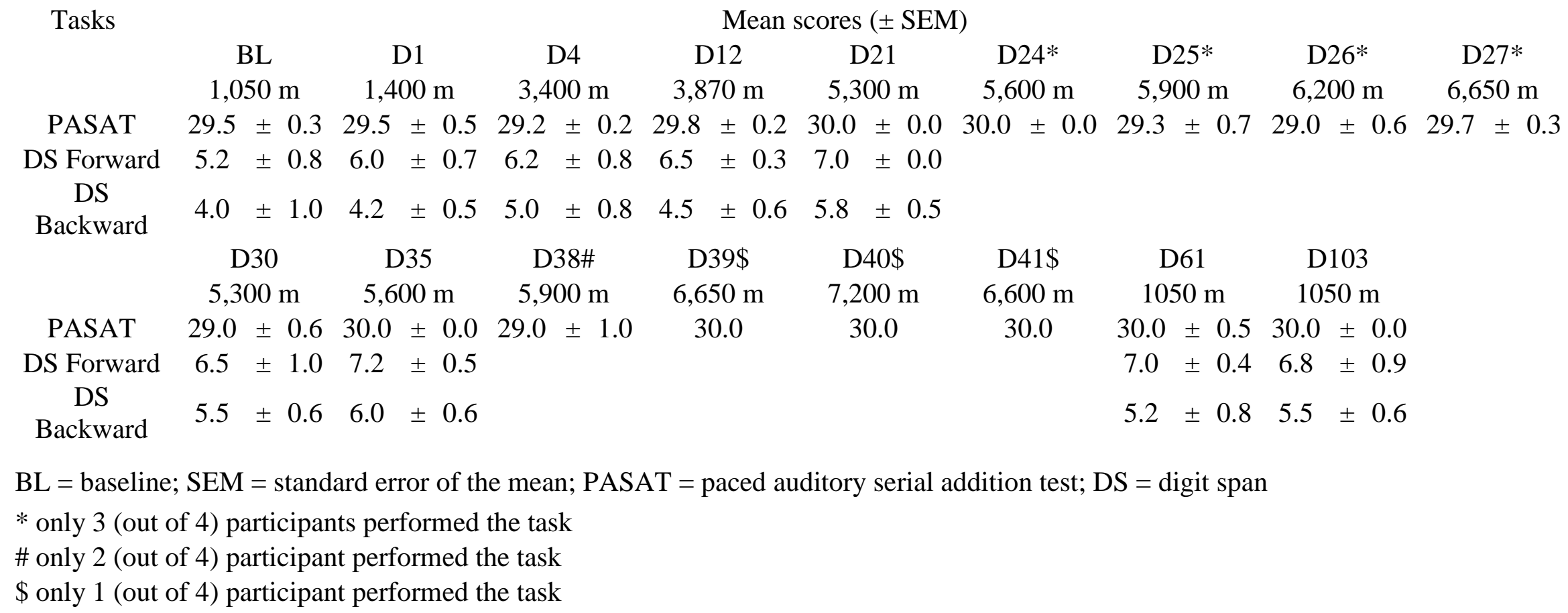

$\mathrm{BL}=$ baseline; $\mathrm{SEM}=$ standard error of the mean; PASAT $=$ paced auditory serial addition test DS = digit span

* only 3 (out of 4) participants performed the task \# only 2 (out of 4) participant performed the task

\$ only 1 (out of 4) participant performed the task 